BULLETIN Bulletin hispanique

HISPANIQUE Université Michel de Montaigne Bordeaux

$122-2 \mid 2020$

L'épithalame en Espagne

Juan Vadillo, Federico García Lorca, Romancero gitano. De la tradición a las vanguardias

México, Bonilla Artigas Editores, 2020

Jacques Issorel

\title{
CpenEdition
}

Journals

Édition électronique

URL : http://journals.openedition.org/bulletinhispanique/11933

DOI : 10.4000/bulletinhispanique. 11933

ISBN : 1775-3821

ISSN : 1775-3821

Éditeur

Presses universitaires de Bordeaux

Édition imprimée

Date de publication : 20 décembre 2020

Pagination : 775-776

ISBN : 979-10-300-0606-3

ISSN : 0007-4640

Référence électronique

Jacques Issorel, « Juan Vadillo, Federico García Lorca, Romancero gitano. De la tradición a las vanguardias », Bulletin hispanique [En ligne], 122-2 | 2020, mis en ligne le 14 décembre 2020, consulté le 19 janvier 2021. URL : http://journals.openedition.org/bulletinhispanique/11933 ; DOI : https://doi.org/ 10.4000/bulletinhispanique.11933

Ce document a été généré automatiquement le 19 janvier 2021.

Tous droits réservés 


\section{Juan Vadillo, Federico García Lorca, Romancero gitano. De la tradición a las vanguardias}

México, Bonilla Artigas Editores, 2020

Jacques Issorel

\section{RÉFÉRENCE}

Juan Vadillo, Federico García Lorca, Romancero gitano. De la tradición a las vanguardias, México, Bonilla Artigas Editores, 2020, 247 p. (Estudios literarios, 1).

1 Le livre s'ouvre sur une édition intégrale des dix-huit poèmes du plus célèbre recueil poétique de Federico García Lorca. Celle-ci, à partir de la page 61, cède le pas à l'étude annoncée par le titre de l'ouvrage et dédiée au grand hispaniste James Valender. Professeur de littérature moderne et contemporaine à la Faculté des lettres de l'UNAM (Universidad Nacional Autónoma de México), Juan Vadillo Comesaña est aussi poète ( $E l$ paisaje es un verso de olvido, 2016) et musicologue. C'est sous ce triple point de vue qu'il envisage son approche du Romancero gitano. Le début de l'introduction fixe bien le cap que tiendra l'auteur tout au long des trois parties de son travail : «Estudiar cómo García Lorca crea su Romancero gitano a partir de la tradición popular andaluza, específicamente de coplas y romances, para transformarla en una poesía altamente sofisticada, que no por ello deja de ser tradicional» (p.69). La première partie («Nueve conferencias, nueve perspectivas») propose une analyse minutieuse de ces conférences prononcées de 1922 («Importancia histórica y artística del primitivo canto andaluz llamado cante jondo») à 1935 («Conferencia recital del Romancero gitano»). Vadillo soumet les conférences successives à une lecture diachronique, ce qui l'amène à souligner, exemples à l'appui, le caractère contradictoire de l'esthétique lorquienne. Le poète, écrit-il, n'adopte jamais «una postura estética definitiva» (p. 106). Au fil des années, les perspectives se croisent et s'enrichissent mutuellement. Cette observation conduit l'auteur à une seconde lecture, 
synchronique, cette fois, qui lui permet de définir l'esthétique du Romancero comme «un diálogo vital y contrapuntístico» (p. 126).

Après une série de pages consacrées au rôle joué par les mouvements surréaliste et ultraïste dans le processus créatif du Romancero gitano, la deuxième partie de l'étude s'intéresse, à la lumière des travaux d'Ángel Álvarez de Miranda, aux «coincidencias entre la lírica tradicional y la religiosidad naturalística» au sein du recueil (p. 145). Dans ces pages, et en accord avec des critiques tels que Mariana Masera, Christian de Paepe, Margit Frenk ou Gaston Bachelard, quelques-uns des grands symboles lorquiens, tels que le sang, l'eau, la lune, l'oliveraie, l'orange et les joncs font l'objet d'intéressantes remarques.

3 Les symboles encore, en particulier ceux que la poésie lyrique traditionnelle offre au poète, nourrissent la troisième partie de l'étude. Juan Vadillo reprend à son compte, en les commentant, les observations de Stephen Reckert quant au «sentido antitético (coincidentia oppositorum)» d'autres symboles, tels que le vent, le fleuve, le citron, l'orme et le figuier. En rappelant que dans sa «Conferencia recital del Romancero gitano» García Lorca «advierte que en su libro hay un solo personaje, la Pena» (p. 207), l'auteur s'attache ensuite à montrer comment la Pena («una manera de sentir la vida con dolor», ibid.) implique la présence simultanée de la vie et de la mort. Les trois denses notes 106, 107, 108 éclairent bien cet aspect de la création lorquienne.

4 À plusieurs reprises, Juan Vadillo revient, à la lumière de la pensée nietzschéenne, sur les deux directions que prend, tour à tour ou dialectiquement, la poésie du Romancero gitano: «Por un lado, Apolo, la claridad, la musa y el ángel; por otro, Dionisos, el duende, la embriaguez» (p.134). Et cite, à ce propos avec bonheur, le propre frère du poète, Francisco García Lorca: «[Federico] libró su propia batalla entre la libertad y la disciplina artísticas» (p. 108).

Ce livre, où sont généreusement signalés les apports des plus prestigieux exégètes du Romancero gitano, sera d'une grande utilité pour les étudiants : ils y trouveront toutes les remarques et réflexions nécessaires à leur propre approche du texte. Une reproduction de la couverture de l'édition originale du Romancero lorquien (Ed. de la Revista de Occidente, 1928) et une bibliographie complètent cet ouvrage, sobrement présenté et, quant à l'étude, élégamment rédigé.

\section{AUTEURS}

JACQUES ISSOREL

Université de Perpignan 